\title{
MEMBANGUN SITUASI KERJA YANG LEBIH MENYENANGKAN PADA KARYAWAN DENGAN PENGADAAN MINUMAN YANG BERGIZI TINGGI
}

\author{
Arundati Shinta, Bimono dan Esti Listiari \\ Fakultas Psikologi Universitas Proklamasi 45 Yogyakarta \\ Email: arundatishinta@yahoo.com
}

\begin{abstract}
Objective of this research is to verify the relationship between the availability of the free of charge of nutritious drink with the pleasing work situation. The second objective is to verify the relationship between the free of charge of nutritious drink with the pro-environment behavior emergence. Thirty (17 women, 13 men) employees participate in this research. They have consumed free of charge of nutrition drink. This research revealed that the free of charge of the nutrition drink enhance more the work situation, compare to the non-free of charge (chi-square $=7.778$, asymptotic significance .005 or $\mathrm{p}<.01)$. The second result is that the free of charge of the nutritious drink supports more the pro-environment behavior emergence, compare to the non-free of charge (chi-square $=4.537$, asymptotic significance .033 or $\mathrm{p}<.01$ ). The pro-environment behavior is also sustained by their willingness to bring some household packaging waste.
\end{abstract}

Key words: nutritious, work situation, pro-environment behavior

\begin{abstract}
Abstrak
Tujuan penelitian yaitu untuk membuktikan adanya hubungan antara tersedianya minuman bergizi tinggi secara gratis dengan situasi kerja yang menyenangkan. Tujuan kedua yaitu untuk membuktikan adanya hubungan antara tersedianya minuman bergizi tinggi secara gratis dengan munculnya perilaku pro-lingkungan hidup. Penelitian ini melibatkan 30 karyawan (17 perempuan, 13 laki-laki). Mereka telah mengkonsumsi minuman sereal bergizi tinggi yang disediakan secara gratis oleh seorang pimpinan organisasi. Tujuan menyediakan minuman bergizi tersebut adalah untuk mendorong terjadinya situasi kerja yang menyenangkan karena perut karyawan telah kenyang. Hasil penelitian menunjukkan bahwa minuman bergizi yang disajikan dengan cara gratis erat hubungannya dengan situasi kerja yang menyenangkan daripada minuman yang disajikan dengan cara tidak gratis (chi square $=7.778$, dengan asymtotic significance 0,005 atau $\mathrm{p}<0,01$ ). Selanjutnya minuman yang disajikan dengan gratis mendorong responden untuk lebih berperilaku mendukung lingkungan hidup daripada ketika minuman disajikan dengan cara tidak gratis (chi-square $=4,537$, dengan asymtotic significance 0,033 atau $\mathrm{p}<0,01$ ). Lingkungan hidup itu juga didukung oleh kesediaan subjek untuk membawa limbah kemasan berbagai produk dari rumah ke tempat kerja.
\end{abstract}

Kata-kata kunci: bergizi, situasi kerja, lingkungan hidup.

ituasi kerja yang menyenangkan ditandai dengan bersemangatnya karyawan dalam berkarya. Karya itu demi terwujudnya organisasi yang lebih baik dan lebih maju daripada hari-hari sebelumnya. Karyawan yang bersemangat tinggi tentu tidak diperoleh dalam 
waktu sekejap. Organisasi sudah bersusah payah mendidik karyawannya agar bermotivasi tinggi, antara lain dengan cara sistem seleksi yang jujur, pelatihan yang berguna untuk menyelesaikan berbagai masalah kerja, pembayaran gaji yang memperhatikan prinsip UMP (Upah Minimum Propinsi), promosi karir yang jelas, asuransi yang membuat karyawan merasa aman, dan masih banyak strategi yang dilakuan bagian personalia organisasi (Probst, 2002; Riggio, 2003; Shinta, Yudhawati \& Yosef, 2012; Wijono \& Shinta, 2012).

Kenyataan yang ada di lapangan, tidak sedikit situasi kerja organisasi menjadi tidak menyenangkan serta tidak sehat. Banyak keluhan yang terdengar, antara lan tentang rendahnya gaji, pemimpin organisasi yang kejam, beban kerja yang terlalu berat, kepuasan kerja yang redah, dan lingkungan kerja yang kotor. Apakah organisasi akan bergeming melihat para karyawannya yang 'menderita' seperti itu? Pada banyak organisasi, keluhankeluhan karyawan tentu akan ditangani dengan segera, bahkan mungkin saja keluhan tersebut justru menjadi sumber penelitian bagi para psikolog industri (Riggio, 2003).

Dasar dilakukannya penelitian ini adalah adanya observasi awal tentang situasi kerja karyawan yang tidak menyenangkan pada suatu organisasi. Indikator situasi yang tidak menyenangkan itu antara lain pelayanan pada konsumen lama, karyawan sering menundanunda penyelesaian tugas, karyawan sering terlambat datang ke kantor, dan peraturan kerja dalam organisasi sering tidak dipatuhi. Pelayanan yang tidak nyaman itu juga ditampilkan pada pagi hari. Pada pagi hari, karyawan datang tepat waktu namun tugas pertama yang dilakukan adalah makan pagi, bukan menyalakan komputer. Acara makan pagi pun, cenderung dilakukan dalam waktu lama sambil bercakap-cakap dengan sesama karyawan yang juga makan pagi. Bagian kepersonaliaan juga sering mengeluh tentang sulitnya mengelola teman-teman karyawan untuk menampilkan kinerja yang lebih baik. Dampak situasi yang tidak menyenangkan tersebut produktivitas dan pelayanan kepada pelanggan menurun (Sonnentag \& Frese, 2003).

Keunikan penelitian ini adalah adanya upaya untuk membuat situasi kerja karyawan yang menyenangkan dengan cara menyediakan minuman bergizi tinggi dan mengenyangkan. Memang diakui bahwa membuat situasi kerja yang menyenangkan tidak hanya dengan menyediakan makan pagi saja, namun ada variabel lain yang jauh lebih kuat pengaruhnya. Variabel lain itu antara lain kepemimpinan yang kuat, situasi kerja yang tidak mengandung stress yang berlebihan, budaya organisasi yang kuat, promosi yang jelas, standar gaji yang memadai, dan masih banyak variabel lainnya. Penekanan penelitian ini adalah pada upaya memperkuat ketahanan fisik karyawan dalam menghadapi beban kerja yang berat. Penelitian ini lebih berpihak pada karyawan, bukan pimpinan, karena karyawan lebih sering berada pada posisi terpojok (Huysse-Gaytandjieva, Groot \& Pavlova, 2013). Mereka tidak mungkin keluar dari tempat kerjanya sekarang meskipun situasi kerja tidak menyenangkan, karena angka pengangguran tinggi.

Tujuan penelitian ini yaitu untuk membuktikan adanya hubungan antara tersedianya minuman bergizi tinggi secara gratis dengan situasi kerja yang menyenangkan. Tujuan kedua yaitu untuk membuktikan adanya hubungan antara tersedianya minuman bergizi tinggi secara gratis dengan munculnya perilaku pro-lingkungan hidup. Manfaat penelitian adalah untuk memberikan pencerahan pada para karyawan dan pembaca bahwa sarapan pagi berupa minuman bergizi tinggi penting untuk memperbaiki situasi kerja. Manfaat selanjutnya adalah memberi inspirasi pada karyawan bahwa bungkus kemasan minuman tersebut dapat didaur ulang. Syaratnya adalah bungkus kemasan tersebut dikumpulkan, tidak dibuang begitu saja. Secara tidak langsung karyawan telah 'dididik' untuk berperilaku prolingkungan hidup yaitu dengan strategi memberikan sesuatu (meskipun kecil / sedikit) terlebih dahulu, sehingga orang-orang akan berusaha membalas kebaikan tersebut (Futera Sustainaility Communication, 2010). 


\section{Makan Pagi dan Situasi Kerja}

Makan pagi penting bagi kesehatan, dan kuat pengaruhnya terhadap kinerja karyawan. Hal ini tercermin pada penelitian yang melibatkan 870 perawat di Inggris (Chaplin \& Smith, 2011). Hasil penelitiannya menyebutkan bahwa $62 \%$ perawat yang menyempatkan diri untuk makan pagi menunjukkan lebih rendahnya stress yang dialaminya, kesalahankesalahan dalam bekerja menurun, dan kecelakaan kerja juga menurun. Makan pagi juga menyebabkan terjaminnya energi untuk bekerja (Halsey et al., 2011). Suatu buku petunjuk bagi para pimpinan menjelaskan bahwa kebiasaan karyawan yang sering melewatkan makan pagi, telah menjadi sumber stress dalam bekerja (Halloran, 2013).

Makan pagi memang penting dilakukan, namun kenyataan yang ada hanya sedikit karyawan yang menyempatkan diri untuk makan pagi. Alasan-alasan mereka bervariasi. Berbagai penelitian (Halsey et al., 2011; Mogre, Atibilla \& Kandoh, 2013) menyebutkan bahwa alasan karyawan untuk melewatkan makan pagi antara lain merasa kurang waktu, terlambat bangun pagi, tidak ada motivasi untuk menyiapkan makan pagi, ingin badan menjadi lebih langsing, kehilangan selera makan, merasa mual, ingin muntah, lemah dan lelah, masih merasa kenyang, dan merasa makan pagi cukup diganti dengan merokok saja. Makan pagi juga sering dilewatkan pada kelompok mahasiswa yang perguruan tingginya berjauhan dari rumah orangtuanya, sehingga mereka harus tinggal di pondokan atau asrama (Moy et al. 2009). Melewatkan makan pagi merupakan strategi pertahanan hidup pada para karyawan tertentu seperti etnis minoritas, kurang beruntung secara ekonomi, bekerja pada organisasi lemah, tuntutan dan jadwal kerja yang tinggi (Blake et al., 2009).

Situasi kerja yang menyenangkan tidak akan datang begitu saja, namun harus diperjuangkan agar benar-benar terjadi dalam peristiwa sehari-hari. Telah banyak penelitian yang menggagas agar situasi kerja yang menyenangkan tercapai (Riggio, 2003). Salah satu cara untuk membuat situasi kerja yang menyenangkan adalah dengan memastikan bahwa semua karyawan sudah makan pagi. Pada organisasi yang lemah, tentu banyak karyawan yang tidak mampu menikmati sarapan karena gajinya yang kecil. Makan pagi digabung dengan makan siang saja, agar lebih hemat (Blake et al., 2009). Kebiasaankebiasaan menunda atau menggabung makan pagi dengan makan siang, ternyata berdampak pada muramnya situasi kerja karyawan.

Bagaimana memutus rantai fenomena penurunan mutu kerja karena ketiadaan makan pagi? Cara memutus rantai tersebut adalah dengan menyediakan makan pagi berupa minuman sereal bergizi tinggi. Sereal dipilih sebagai menu makan pagi karena menyehatkan (Mwatsama \& Stewart, 2005), harganya terjangkau, sangat dikenal oleh masyarakat, mempunyai banyak variasi rasa, praktis penyajiannya (Forum Kompas, 2013; Pandudiputra, 2011). Alasan selanjutnya dipilihnya minuman bergizi sebagai pengganti sarapan adalah bungkusnya bisa didaur ulang menjadi tas yang cantik (Boronnia, 2013; Helmy, 2014). Tas cantik itu kemudian diberikan kepada karyawan yang paling berprestasi. Jadi penyediaan minuman sereal tidak hanya berdampak pada kesehatan (fisik dan psikhis), namun juga menumbuhkan perilaku pro-lingkungan hidup.

\section{Teori Pertukaran Sosial}

Apa saja respon penerima manfaat dari makanan bergizi tersebut? Respon para penerima manfaat dapat dijelaskan dengan teori pertukaran sosial (the social exchange theory) yang dikemukakan oleh George Homans (dalam Appelrouth \& Edles, 2011; Fisher, 1982). Teori pertukaran sosial tersebut menjelaskan bahwa dalam setiap situasi sosial individu akan selalu menimbang-nimbang antara cost (pengorbanan atau ongkos) yang harus dikeluarkannya dan reward (imbalan atau keuntungan) yang diperolehnya. Apabila pengorbanan yang dikeluarkannya akan melebihi imbalan yang diterimanya, maka individu cenderung menghentikan relasi 
sosialnya. Jadi dalam situasi sosial itu tentu ada 'sesuatu' yang saling dipertukarkan.

Dalam teori pertukaran sosial tersebut sesungguhnya terjadi tiga macam sifat pertukaran. Tiga sifat tersebut adalah pertukaran yang mengikuti pola-pola saling ketergantungan (interdependent exchange), pertukaran atas dasar keyakinan, dan pertukaran berdasarkan norma moral (Cropanzano \& Mitchell, 2005). Dalam penelitian ini, pertukaran yang berdasar keyakinan dan norma moral kurang sesuai. Hal ini karena pertukaran berdasarkan keyakinan lebih menekankan pada prinsip-prinsip budaya, yang sangat menggantungkan hasil akhir pada konsep waktu. Hal itu berarti semua orang pada akhirnya akan mendapatkan keadilan sesuai dengan yang disumbangkannya. Konsep pertukaran berdasarkan keyakinan ini seolaholah menyerahkan diri pada waktu, bukan pada usaha. Selanjutnya pertukaran berdasarkan norma lebih menekan pada kewajiban, karena hal itu sudah tersirat dalam norma sosial. Pihak penerima kebaikan wajib (harus) membalas kebaikan ketika ia menerima kebaikan dari pihak pemberi. Agar terjadi suatu perubahan sosial, maka pendekatan yang sifatnya wajb (keharusan) cenderung mendapat penolakan.

Untuk suatu perubahan sosial, seperti suasana kerja menjadi lebih menyenangkan, maka pertukaran sosial yang paling sesuai adalah pertukaran yang bersifat ketergantungan. Pertukaran yang berdasarkan azas saling ketergantungan adalah transaksi yang terjadi antar individu dalam satu kelompok. Satu individu berperilaku tertentu maka pihak lain di sekelilingnya akan meresponnya. Ketika individu memberikan suatu keuntungan maka orang-orang di sekelilingnya akan membalas juga dengan kebaikan. Situasi semacam ini lazim berada pada situasi perubahan sosial. Jadi satu tindakan telah menyulut tindakan-tindakan kebaikan berikutnya dari lingkungan sosialnya (Cropanzano \& Mitchell, 2005).

Apa saja yang dipertukarkan dalam situasi sosial tersebut? Foa dan Foa (dalam Cropanzano \& Mitchell, 2005) menjelaskan bahwa ada enam sumber pertukaran sosial yatu cinta, status, informasi, uang, barang-barang berharga, dan pelayanan. Ketika seorang pimpinan berinisiatif memberikan suatu stimulus berupa minuman yang bergizi tinggi untuk membuat situasi kerja menjadi lebih menyenangkan, dan stimulus itu harganya sangat terjangkau maka stimulus itu bersifat simbol saja. Stimulus simbol tersebut pada hakekatnya akan menyampaikan harapan yang jauh melampaui tujuan pemberian stimulus itu (Cropanzano \& Mitchell, 2005). Jadi pemberian minuman bergizi tinggi itu tidak hanya bertujuan membuat perut karyawan kenyang, tetapi juga akan membuat karyawan merasa diperhatikan sehingga mereka membalasnya dengan cara meningkatkan pelayanan.

Dalam teori pertukaran sosial tersebut juga dibahas tentang cost atau pengorbanan. Pengorbanan dalam penelitian ini adalah individu diandaikan berhadapan dengan situasi yang menuntutnya untuk membayar harga minuman bergizi tersebut. Apakah ia masih tetap bersedia memberikan pelayanan yang lebih baik? Harga minuman bergizi itu sesungguhnya sangat terjangkau, sehingga sebenarnya karyawan pasti mampu untuk menyediakan minuman itu paling tidak untuk keperluan dirinya sendiri. Oleh karena harganya terjangkau namun manfaatnya dirasakan sesuai dengan kebutuhan, maka individu seharusnya bersedia mengadakan sendiri minuman itu. Mereka tidak perlu menunggu donatur untuk membiayai minuman tersebut. Oleh karena keberadaan minuman bergizi itu lebih merupakan simbol, maka individu cenderung enggan mengeluarkan uang untuk membeli minuman tersebut. Hal ini menunjukkan bahwa sesuatu yang bersifat simbol (intangible), cenderung dipersepsikan mahal. Situasi ini seperti fenomena balas dendam. Individu yang tersinggung harga dirinya (harga diri adalah intangible) maka ia akan berusaha sekuat tenaga untuk membalasnya, termasuk mengeluarkan uang yang tidak terhingga banyaknya demi terbalaskan dendamnya (Cropanzano \& Mitchell, 2005). 
Dalam penelitian ini, pengorbanan selanjutnya adalah kesediaan individu untuk mengumpulkan kemasan bungkus minuman tersebut. Mengumpulkan kemasan minuman adalah suatu tindakan yang sederhana, sehingga dipersepsikan bukan sebagai pengorbanan. Ketika minuman bergizi itu tidak lagi gratis, maka mengumpulkan kemasan dipersepsikan sebagai pengorbanan yang tinggi. Hal ini karena terjadi ketidakseusaian (mismatch) antara prinsip ekonomi (minuman yang tidak gratis) dengan hubungan sosial (ajakan untuk mengumpulkan kemasan bungkus minuman) (Cropanzano \& Mitchell, 2005). Apalagi bila ajakan itu diperluas menjadi ajakan mengumpulkan kemasan bungkus berbagai produk dari rumah sendiri, maka ajakan itu dipersepsikan semakin tidak menguntungkan.

Hipotesis penelitian ini adalah ada hubungan antara tersedianya minuman bergizi tinggi dengan situasi kerja. Bila minuman tersebut diadakan secara gratis, maka situasi kerja karyawan menjadi lebih menyenangkan. Hipotesis kedua adalah ada hubungan antara tersedianya minuman bergizi tinggi dengan munculnya perilaku pro-lingkungan hidup. Bila minuman tersebut diadakan secara gratis, maka karyawan cenderung bersedia berperilaku prolingkungan hidup.

\section{METODE}

a. Partisipan. Penelitian ini melibatkan 30 orang karyawan pada suatu organisasi. Tiga puluh karyawan tersebut terdiri dari 17 perempuan dan 13 laki-laki. Rerata pendidikan reponden adalah sedikit di bawah sarjana $\mathrm{S} 1$ atau 15 tahun (perempuan 16 tahun, laki-laki 14 tahun). Lama kerja mereka juga bervariasi, dengan rerata lama kerja 15 bulan.

b. Desain. Desain penelitian ini adalah deskriptif kuantitatif. Penelitian ini bersifat deskriptif karena peneliti ingin memotret suatu gejala, peristiwa, atau fenomena yang sudah ada atau sedang terjadi secara apa adanya. Penelitian ini tidak membutuhkan suatu intervensi, mengontrol, atau memanipulasi suatu variabel. Penelitian ini tidak hendak mencari hubungan sebab akibat (Warfield, 2005). Oleh karena itu hasil penelitian ini hanya berlaku pada saat sekarang, namun hasil itu mungkin saja kurang relevan untuk masa yang akan datang (Neville, 2007). Penelitian ini juga bersifat kuantitatif karena jenis data yang diperoleh adalah nominal, sehingga analisis data yang digunakan adalah analisis tabulasi silang.

c. Prosedur. Penelitian ini pada mulanya melibatkan 31 karyawan suatu lembaga. Salah satu pimpinan lembaga menyediakan minuman bergizi tinggi. Maksud pimpinan tersebut adalah untuk membantu para karyawan yang kesulitan makan pagi. Hal ini karena makan pagi erat hubungannya dengan situasi kerja yang menyenangkan, dan menjauhkan karyawan dari stress kerja. Karyawan dipersilakan mengambil sendiri minuman bergizi tinggi itu secara gratis, namun syaratnya adalah bungkus kemasannya dikumpulkan lagi. Bungkus kemasan itu didaur ulang untuk dijadikan sebuah tas cantik. Setelah karyawan menikmati minuman tersebut selama dua bulan, kemudian kuesioner diedarkan. Dari 31 kuesioner yang diedarkan, ternyata hanya 30 saja yang lengkap. Satu karyawan menolak meneruskan pengisian kuesioner karena merasa sering tidak mendapatkan kesempatan mengkonsumsi minuman tersebut. Jumlah karyawan semuanya adalah 40 orang, namun hanya 31 orang saja yang pernah mengkonsumsi minuman bergizi tersebut. Karyawan yang sama sekali belum pernah mengkonsumsi minuman tersebut tidak dilibatkan dalam penelitian. Jadi sampel penelitian ini adalah sama dengan populasinya. Hal ini dapat dilakukan karena jumlah orang yang terlibat dalam penelitian tidak banyak.

d. Alat ukur. Alat ukur penelitian ini adalah sebuah kuesioner yang terdiri atas tujuh pertanyaan. Penekanan pada tiga pertanyaan pertama (butir nomo1, 2, dan 3) adalah pernyataan bahwa minuman bergizi 
tinggi ini sifatnya gratis. Contoh pertanyaan butir nomor 1 pada kuesioner adalah "Ada banyak dampak dari ketersediaan minuman bergizi tinggi yang disediakan secara gratis di kantor ini. Menurut pendapat Anda, mana dampak yang paling relevan dengan situasi kerja karyawan?". Butir pertanyaan nomor 4 adalah untuk memastikan bahwa responden memang benar-benar membutuhkan minuman bergizi ini. Penekanan pertanyaan nomor 5-7 adalah pada pernyataan bahwa ketersediaan minuman Bergizi ini tidak gratis. Dalam penelitian ini, konsep tidak gratis berarti karyawan diminta untuk mencari sendiri sponsor pengadaan minuman yang menyehatkan ini. Contoh pertanyaan nomor 5 adalah "Bila ketersediaan minuman menyehatkan ini diteruskan dan Anda diminta mencari sendiri sponsornya, maka apa dampak pada situasi kerja Anda?. Berikut adalah daftar pertanyaan pada kuesioner.

Tabel 1. Garis besar pertanyaan pada kuesioner penelitian

\begin{tabular}{|c|c|c|}
\hline Butir & Topik pertanyaan & Alternatif jawaban \\
\hline No. 1 & $\begin{array}{l}\text { Dampak tersedianya minuman } \\
\text { bergizi gratis pada situasi kerja. }\end{array}$ & $\begin{array}{l}\text { - Menyenangkan } \\
\text { - Tidak menyenanangkan } \\
\text { - Biasa saja }\end{array}$ \\
\hline No. 2 & $\begin{array}{l}\text { Hubungan antara ketersediaan } \\
\text { minuman bergizi secara gratis } \\
\text { dengan perilaku pro-lingkungan } \\
\text { hidup. }\end{array}$ & $\begin{array}{l}\text { - Bersedia kumpulkan bungkus } \\
\text { minuman } \\
\text { - Tidak bersedia } \\
\text { - Biasa saja }\end{array}$ \\
\hline No. 3 & $\begin{array}{l}\text { Hubungan antara ketersediaan } \\
\text { minuman bergizi secara gratis } \\
\text { dengan perilaku pro-lingkungan } \\
\text { hidup. }\end{array}$ & $\begin{array}{l}\text { - Bersedia kumpulkan limbah kemasan } \\
\text { dari rumah } \\
\text { - Tidak bersedia } \\
\text { - Biasa saja }\end{array}$ \\
\hline No. 4 & $\begin{array}{l}\text { Keberlangsungan ketersediaan } \\
\text { minuman Bergizi }\end{array}$ & $\begin{array}{l}\text { - Diteruskan } \\
\text { - Dihentikan }\end{array}$ \\
\hline No. 5 & $\begin{array}{l}\text { Dampak tersedianya minuman } \\
\text { Bergizi yang tidak gratis pada situasi } \\
\text { kerja. }\end{array}$ & $\begin{array}{l}\text { - Menyenangkan } \\
\text { - Tidak menyenanangkan } \\
\text { - Biasa saja }\end{array}$ \\
\hline No. 6 & $\begin{array}{l}\text { Hubungan antara ketersediaan } \\
\text { minuman bergizi secara tidak gratis } \\
\text { dengan perilaku pro-lingkungan } \\
\text { hidup. }\end{array}$ & $\begin{array}{l}\text { - Bersedia kumpulkan bungkus } \\
\text { minuman } \\
\text { - Tidak bersedia } \\
\text { - Biasa saja }\end{array}$ \\
\hline No. 7 & $\begin{array}{l}\text { Hubungan antara ketersediaan } \\
\text { minuman bergizi secara tidak gratis } \\
\text { dengan perilaku pro-lingkungan } \\
\text { hidup. }\end{array}$ & $\begin{array}{l}\text { - Bersedia kumpulkan limbah kemasan } \\
\text { dari rumah } \\
\text { - Tidak bersedia } \\
\text { - Biasa saja }\end{array}$ \\
\hline
\end{tabular}

Tabel 1 memperlihatkan bahwa alternatif jawaban pada kuesioner penelitian ada 3 . Dalam analisis statistik tabulasi silang, maka alternatif jawaban netral (biasa saja) dikelompokkan menjadi alternatif jawaban yang negatif (tidak menyenangkan, tidak bersedia). e. Teknik analisis. Penelitian ini juga bersifat kuantitatif, dan disain statistik yang digunakan yaitu analisis tabulasi silang (crosstab atau chi-square). Analisis tabulasi silang ini digunakan karena jenis data adalah nominal sehingga bersifat frekuensi. Analisis tabulasi silang termasuk statitik non-parametrik. Analisis ini juga dipilih karena jumlah respondennya terlalu sedikit 
sehingga data yang diperoleh tidak mampu memenuhi asumsi yang mendasari statistik parametrik (Downie \& Heath, 1974).

\section{HASIL}

Penelitian awal ini melibatkan 31 responden namun satu responden menolak melanjutkan pengisian kuesioner. Jadi penelitian ini hanya melibatkan 30 reponden (17 perempuan dan 13 laki-laki). Hasil pengumpulan data dapat dilihat pada tabel di bawah ini.

Tabel 2. Jawaban responden tentang situasi di tempat kerja dan hubungannya dengan tersedianya minuman bergizi di tempat kerja

\begin{tabular}{|l|c|c|}
\hline \multicolumn{1}{|c|}{ Jenis } & $\begin{array}{c}\text { Minuman } \\
\text { repon } \\
\text { bergizi } \\
\text { tersedia } \\
\text { secara gratis }\end{array}$ & $\begin{array}{c}\text { Minuman } \\
\text { bergizi tersedia } \\
\text { secara tidak } \\
\text { gratis }\end{array}$ \\
\hline $\begin{array}{l}\text { Positif di } \\
\text { tempat } \\
\text { kerja } \\
\begin{array}{l}\text { Negatif di } \\
\text { tempat } \\
\text { kerja }\end{array}\end{array}$ & $70 \%$ & $20 \%$ \\
\hline
\end{tabular}

Sumber: Data rimer

Pada tabel 2 tersebut terlihat bahwa tanggapan positif responden terhadap tersedianya minuman bergizi adalah jauh lebih tinggi daripada tanggapan negatif. Hal ini juga tercermin pada hitungan hipotesis pertama yang menggunakan analisis chi-square $2 \times 2$. Kelompok baris adalah cara menyediakan minuman bergizi (gratis $\mathrm{x}$ tidak gratis). Kelompok kolom adalah dampak minuman bergizi terhadap situasi kerja (menyenangkan $\mathrm{x}$ tidak menyenangkan).

Hasil perhitungan statistik deskriptif adalah ada hubungan antara cara penyediaan minuman bergizi dengan situasi kerja. Minuman bergizi yang disajikan dengan cara gratis, menunjukkan adanya situasi kerja yang menyenangkan daripada minuman yang disajikan dengan cara tidak gratis (chi square = 7.778, dengan asymtotic significance 0,005 atau $\mathrm{p}<0,01)$. Selain alasan menyenangkan, alasan positif lainnya yang mendukung tersedianya minuman bergizi adalah pendapatpendapat seperti menyehatkan, sebagai pengganti sarapan, mengakrabkan temanteman, menunda rasa lapar, dan memberdayakan teman-teman.

Tabel 3. Jawaban responden tentang lingkungan hidup dan hubungannya dengan tersedianya minuman bergizi di tempat kerja

\begin{tabular}{|l|c|c|}
\hline Jenis repon & $\begin{array}{c}\text { Minuman } \\
\text { bergizi } \\
\text { tersedia } \\
\text { secara gratis }\end{array}$ & $\begin{array}{c}\text { Minuman } \\
\text { bergizi } \\
\text { tersedia } \\
\text { secara tidak } \\
\text { gratis }\end{array}$ \\
\hline $\begin{array}{l}\text { Pro } \\
\text { lingkungan } \\
\text { hidup } \\
\text { Tidak pro } \\
\text { lingkungan } \\
\text { hidup }\end{array}$ & $76.7 \%$ & $13.3 \%$ \\
\hline
\end{tabular}

Sumber: Data rimer

Hipotesis kedua juga dianalisis dengan chi-square $2 \times 2$. Kelompok baris adalah cara menyediakan minuman bergizi (gratis $\mathrm{x}$ tidak gratis). Kelompok kolom adalah perilaku tentang lingkungan hidup (mendukung $\mathrm{x}$ tidak mendukung lingkungan hidup).

Hasil perhitungan statistik deskriptif adalah ada hubungan antara cara penyediaan minuman bergizi dengan perilaku terhadap lingkungan hidup. Minuman yang disajikan dengan gratis mendorong responden untuk lebih berperilaku mendukung lingkungan hidup daripada ketika minuman disajikan dengan cara tidak gratis (chi-square $=4,537$, dengan asymtotic significance 0,033 atau $\mathrm{p}<0,01)$. Perilaku mendukung lingkungan hidup itu juga didukung oleh kesediaan mereka untuk membawa limbah kemasan berbagai produk dari rumah ke tempat kerja (17 responden atau $56.7 \%$ ). Hal yang menarik adalah dari 17 responden tersebut, ternyata $64 \%$ adalah perempuan dan $36 \%$ adalah laki-laki. 


\section{PEMBAHASAN}

Tujuan penelitian ini adalah untuk membutikan hubungan antara tersedianya minuman bergizi dengan situasi kerja karyawan pada suatu organisasi. Ketersediaan minuman bergizi tersebut dibedakan dengan dua cara yaitu secara gratis dan responden diminta mencari sendiri sponsornya. Seperti diduga, ketersediaan minuman bergizi secara gratis lebih memberikan respon positif (menyenangnkan, menambah semangat kerja), daripada ketika responden diminta mencari sponsor untuk mengadakan minuman tersebut. Bahkan ada dua responden yang mengatakan bahwa tugas mencari sponsor akan mengganggu konsentrasi kerja. Situasi seperti ini sesuai dengan teori pertukaran sosial bahwa individu akan selalu mengevaluasi situasi di sekelilingnya. Individu akan memberi evaluasi lebih positif pada situasi yang lebih menguntungkannya daripada situasi yang tidak menguntungkannya.

Tujuan penelitian kedua yaitu untuk membuktikan hubungan antara tersedianya minuman bergizi dengan perilaku terhadap lingkungan hidup. Ketersediaan minuman bergizi dengan cara gratis lebih kuat hubungannya dengan perilaku mendukung lingkungan hidup, daripada ketika responden diminta mencari sponsor untuk mengadakan minuman tersebut. Seperti diduga, mengkonsumsi secara gratis minuman bergizi kemudian mengumpulkan bungkusnya, bukanlah hal yang berat (Kollmuss \& Agyeman, 2000). Kesediaan mereka untuk menampilkan perilaku cinta pada lingkungan hidup tersebut juga konsisten dengan kesediaannya untuk membawa limbah kemasan berbagai produk dari rumah untuk dibawa ke tempat kerja. Konsistensi perilaku positif itu ditampilkan oleh 23 responden atau $76.7 \%$. Responden yang perilakunya tidak konsisten yaitu hanya cinta lingkungan ketika berada di tempat kerja, namun menolak membawa limbah dari rumah ditampilkan oleh 3,3\% responden.

Konsistensi perilaku dan perilaku cinta pada lingkungan hidup lebih banyak ditampilkan oleh responden perempuan daripada laki-laki. Perempuan lebih bersedia untuk repot membawa limbah kemasan dari rumah ke tempat kerja dan kemudian akan didaur ulang secara kolektif. Gejala ini juga ditemukan dalam penelitian dengan data sekunder yang melibatkan 22 bangsa di Eropa (Hunter, Hatch \& Johnson, 2004). Hal ini mungkin karena perempuan lebih senang dengan kebersihan, ketelitian, dan kenyamanan hidup daripada laki-laki. Selain itu rerata tingkat pendidikan perempuan yang lebih tinggi (16 tahun) daripada laki-laki (14 tahun), mungkin juga berpengaruh terhadap kesediaan perempuan untuk berperilaku pro-lingkungan hidup. Meskipun sebenarnya pendidikan tidak selalu menjamin terjadinya perilaku prolingkungan hidup (Kollmuss \& Agyeman, 2002).

\section{KESIMPULAN DAN SARAN}

Penelitian ini menjelaskan bahwa dalam semua situasi sosial, individu akan selalu menimbang-nimbang antara imbalan yang diperolehnya dan pengorbanan yang harus dibayarkannya. Ketika pengorbanan dirasakan lebih tinggi daripada imbalannya, maka individu cenderung menghentikan hubungan sosial. Dalam penelitian ini, imbalan adalah kesempatan untuk mengkonsumsi minuman bergizi dengan gratis. Pengorbanan adalah ketika individu diminta untuk mengadakan sendiri minuman bergizi tersebut. Hubungan sosialnya adalah terlibat dalam situasi kerja dan munculnya perilaku pro-lingkungan hidup. Ketika individu mendapat minuman bergizi dengan gratis, maka situasi kerjanya menjadi menyenangkan. Ketika individu mendapat minuman bergizi tinggi, maka perilakunya menjadi pro-lingkungan hidup.

Keterbatasan penelitian adalah sedikitnya responden yang terlibat dalam penelitian. Bila jumlah responden lebih banyak, maka generalisasi penelitian akan semakin meyakinkan. Keterbatasan selanjutnya adalah penelitian ini hanya dilakukan pada satu organisasi saja. Hal ini dilakukan untuk mencapai homogenitas responden. Bila penelitian ini dilakukan pada banyak organisasi yang sejenis, maka generalisasi hasil penelitian 
akan semakin mudah dilakukan. Oleh karena itu penelitian yang akan datang hendaknya mempertimbangkan jumlah responden dan jumlah organisasi asal responden tersebut.

\section{DAFTAR RUJUKAN}

Appelrouth, S. \& Edles, L.D. (2011). Sociological theory in the contemporary era: Text and readings. ( $2^{\text {nd }}$ Ed.). Los Angeles: Pine Forge Press, an Imprit of SAGE publication, Inc.

Blake, C.E., Devine, C.M., Wethington, E., Jastran, M., Farrell, T., \& Bisogni, C.A. (2009). Employed parents' satisfaction with food-choice coping strategies. Influence of gender and structure. Appetite, June, 52 (3), 711-719.

Boronnia, A.D. (2013). Limbah kemasan plastik sulap kerajinan industri kreatif. Kup45iana. Februari. Retrieved from: http://lintaskampusup45.blogspot.com/20 13/02/limbah-kemasan-plastik-sulapkerajinan.html\#uds-search-results

Chaplin, K. \& Smith, A. P. (2011). Breakfast and snacks: Associations with cognitive failures, minor injuries, accidents and stress. Nutrients, 3, 515-528.

Cropanzano, R. \& Mitchell, M.S. (2005) Social exchange theory: An interdisiplinary review. Journal of Management. 31 (6), December, 874-900.

Downie, N.M., \& Heat, R.W. (1974). Basic statistical methods. ( $4^{\text {th }}$ ed). New York: Harper \& Row, Publishers.

Fisher, R. (1982). Social psychology: An applied approach. New York: St. Martin Press.

Forum Kompas (2013). 5 merek Indonesia yang laris di dunia. Retrieved on May 8, 2013

from:http://forum.kompas.com/teras/2619 28-5-merek-indonesia-yang-laris-didunia.html
Futera Sustainaility Communication (2010). New rules: New game. Retrieved on May 14, 2014 from: http://www.futerra.co.uk/downloads/New Rules_NewGame.pdf

Halloran, A. (2013). Is stress causing a problem in your workplace? Finance \& Management, December.

Halsey, L.G., Huber, J.W., Low, T., Ibeawuchi, C. Woodruff, P. \& Reeves, S. (2011). Does consuming breakfast influence activity levels? An experiment into the effect of breakfast consumption on eating habits and energy expenditure. Public Health Nutrition 15(2), 238-245.

Helmy, C. (2014). Dwi Retnastuti: Menghargai sampah sejak dari rumah. Kompas. 9 Mei, halaman 16.

Hunter, L.M., Hatch, A. \& Johnson, A. (2004). Cross-national gender variation in environmental behaviors. Social Science Quarterly. September, 85(3), 677-694.

Huysse-Gaytandjieva, A.; Groot, W. \& Pavlova, M. (2013). Why do some employees fall into and fail to exit a joblock situation?. Journal of Environmental and Public Health, 2013, Article ID 839349,

http://dx.doi.org/10.1155/2013/839349. Hindawi Publishing Corporation.

Kollmuss, A. \& Agyeman, J. (2002). Mind the gap: Why do people act environmentally and what are the barriers to proenvironmental behavior?. Environmental Education Research. 8(3), 239-260.

Mogre, V., Atibilla, J.A. \& Kandoh, B.N.A. (2013). Association between breakfast skipping and adipodity status among civil servants in the Tamale metropolis. Journal of Medical and Biomedical Sciences. 2(3), 1-7.

Moy, F.M., Johari, S., Ismail, Y., Mahad, R., Tie, F.H. \& Wan Ismail, W.M.A. (2009). Breakfast skipping and its associated factors among undergraduates in a Public 
University in Kuala Lumpur. Mal J Nutr, 15(2), 165-174.

Mwatsama, M. \& Stewart, L. (2005). Food poverty and health: Briefing statement. London: Faculty of Publlic Health of Royal Colleges of Physicians of the United Kingdom.

Neville, C. (2007). Effective learning service : Introduction to research and research methods. UK: Bradford University School of Management.

Pandudiputra. (2011). Jangan melewatkan sarapan pagi. TanyaDok.com. Retrieved on January 17, 2014 from:

http://www.tanyadok.com/kesehatan/jang an-melewatkan-sarapan-pagi

Probst, T.M. (2002). The impact of job insecurity on employee work attitudes, job adaptation, and organizational withdrawal behaviors. In J.M. Brett \& F. Drasgow (Eds.). The psychology of work: Theoretically based empirical research. London: Lawrence Erlbaum Associates, Publishers. Pp. 141-168.

Riggio, R. E. (2003). Introduction to industrial I organizational psychology. New Jersey: Upper Saddle River.

Shinta, A., Yudhawati, D. \& Yosef, LG. (2012). Bekerja pada organisasi yang tidak sehat: Peluang atau kutukan bagi karyawan?. Prosiding Seminar Nasional Peran Budaya Organisasi terhadap Efektivitas dan Efisiensi Organisasi, halaman 1-13. No. ISBN. 978-60218835-2-5. Fakultas Psikologi Universitas Muria Kudus, Jawa Tengah,

Sonnentag, S. \& Frese, M. (2003). Stress in organizations. In W.C. Borman, D.R. Ilgen, R.J. Klimoski \& I.B. Weiner (Eds.) Handbook of psychology: Industrial and organizational psychology. Hoboken, New Jersey: John Wiley \& Sons, Inc. pp. 453-491

Warfield, D. (2005). Is/it research: A research methodologies review. Journal of Theoretical and Applied Information Technology. Pp. 28-35.
Wijono, D. \& Shinta, A. (2012). Kesenjangan antara harapan dan kenyataan: Fenomena kekecewaan karyawan terhadap organisasi. Jurnal Maksipreneur, Manajemen, Koperasi, dan Entrepreneurship. 2 (1), 85-96, Desember. No. ISSN. 2089-5501. Fakultas Ekonomi Universitas Proklamasi 45 Yogyakarta. 
